\title{
METODOLOGIAS ATIVAS NO ENSINO DE FILOSOFIA
}

\section{ACTIVE METHODOLOGIES IN TEACHING PHILOSOPHY}

\author{
METODOLOGÍAS ACTIVAS EN LA ENSEÑANZA DE LA FILOSOFÍA
}

\section{Ícaro Luís Fracarolli Vila ${ }^{1}$}

Jose Petrúcio de Farias Junior ${ }^{2}$

1. Bacharel em Tradução e Interpretação pela Unaerp em 2008, Licenciado em Letras (ing/port) pelo CUBM em 2009, Licenciado em Pedagogia pela Unifran em 2016, Licenciado em Letras (esp/port) pela Unifran (2017), Tecnólogo em Processos Gerenciais (2017) e Gestão comercial (2018) pela UNISA, Licenciado em Filosofia pela UFSJ (2020), Graduando em Ciências Contábeis, Ciências Econômicas, Gestão de TI ,Design Gráfico e Jornalismo pela Unifran. Pós-graduado em mais de 20 áreas do conhecimento. Mestre em Linguística Aplicada pela Universidade de Michigan (2016). Doutor em Linguística e Neurociência pela Yale University (2020). E-mail: vila.icaro1@ gmail.com

2. Licenciado e Bacharel em História pela Universidade Estadual Paulista (UNESP/Franca - 2003), em Pedagogia pela Universidade Federal de São João Del Rei (UFSJ - 2012) e Letras-Inglês (UNIUBE - 2009). Especialista em Educação Empreendedora (UFSJ) e Planejamento, Implementação e Gestão da Educação a Distância (UFF). Mestre em História, na linha de pesquisa História e Cultura Política pela UNESP/Franca (2012), com estágio de pesquisa na Albert Ludwigs Universität Freiburg (2007), Doutor em História também pela UNESP/Franca, com período sanduíche na Freie Universität - Berlin (2011-2012). Pós-Doutor em Educação pela Universidade Federal de Uberlândia (2018). petruciojr@terra.com.br

RESUMO: A Filosofia como disciplina sofreu muitas idas e vindas na educação brasileira, seja por conta da legislação, seja por questões ideológicas e governamentais. Somente em 2008 é que se firmou como obrigatória no ensino médio, por meio da lei 11684. Ela objetiva em levar o aluno a construir conceitos e conseguir autonomia posteriormente. Contudo, há várias possibilidades pedagógicas acerca de como ensiná-la. Por muito tempo, se usou as metodologias tradicionais. Hoje, entretanto, as metodologias ativas são uma excelente alternativa de se atingir tal objetivo, por usarem o protagonismo do aluno como o principal método de ensino. Diante disso, buscou-se analisar dois livros didáticos de Filosofia em amplo uso no estado de São Paulo, a fim de verificar a presença de tais formas de ensinar. Não foi constatado muitos elementos ativos, pois o ensino filosófico ainda é calcado na linha francesa tradicional. Em tempos hipermodernos, é necessária uma remodelação nos métodos de ensinos, com mais eficácia e pertinência à geração atendida.

Palavras-chave: Ensino de filosofia. Metodologias ativas. Livro didático.

\begin{abstract}
Philosophy as a discipline has suffered many comings and goings in Brazilian education, whether because of legislation or ideological and governmental issues. It was only in 2008 that it became mandatory in high school, through law 11684. It aims to lead the student to build concepts and achieve autonomy later. However, there are several pedagogical possibilities on how to teach it. For a long time, traditional methodologies were used. Today, however, active methodologies are an excellent alternative to achieve this goal, because they use the student's protagonism as the main teaching method. In view of this, we sought to analyze two textbooks on Philosophy in wide use in the state of São Paulo, in order to verify the presence of such ways of teaching. Not many active elements were found, since philosophical teaching is still based on the traditional French line. In hypermodern times, a remodeling of teaching methods is necessary, with more efficiency and relevance to the generation attended.
\end{abstract}

Keywords: Teaching philosophy. Active methodologies. Textbook.
RESUMEN: La filosofía como disciplina ha sufrido muchas idas y venidas en la educación brasileña, ya sea por la legislación o por cuestiones ideológicas y gubernamentales. Sólo en 2008 se hizo obligatorio en la escuela secundaria, a través de la ley 11684. Su objetivo es llevar al estudiante a construir conceptos y lograr la autonomía más tarde. Sin embargo, hay varias posibilidades pedagógicas sobre cómo enseñarlo. Durante mucho tiempo se utilizaron metodologías tradicionales. Sin embargo, hoy en día, las metodologías activas son una excelente alternativa para lograr este objetivo, ya que utilizan el protagonismo del estudiante como principal método de enseñanza. En vista de esto, buscamos analizar dos libros de texto de Filosofía de amplio uso en el estado de São Paulo, para verificar la presencia de tales formas de enseñanza. No se encontraron muchos elementos activos, ya que la enseñanza filosófica se basa todavía en la línea tradicional francesa. En tiempos hipermodernos, es necesaria una remodelación de los métodos de enseñanza, con más eficiencia y relevancia para la generación atendida.

Palabras-clave Enseñanza de la filosofia. Metodologías activas. Libro de texto.

Recebido em: 30/06/2020

Aprovado em: 05/11/2020

Todo o conteúdo deste periódico está licenciado com uma licença Creative Commons (CC BY-NC-ND 4.0 Internacional), exceto onde está indicado o contrário. 


\section{Introdução}

O saber filosófico nunca teve uma posição de destaque nas escolas regulares brasileiras. Sempre foi deixado em segundo plano no currículo do Ensino Médio. A Filosofia, como componente curricular do Ensino Médio, está nas escolas como componente obrigatório desde 2008, data que foi promulgada a lei 11.684, obrigando o seu ensino juntamente com a Sociologia. O governo buscou atender uma demanda da sociedade que buscava preparar os alunos de forma mais eficaz para a vida cidadã e para o trabalho.

Esse ambiente de tensão causa incertezas ao professor, que sofre com o querer-fazer-a-diferença, e à instituição, que muitas vezes engessa o fazer didático. A realidade escolar é de dúvidas, pessimismo e ainda não se tem o aporte necessário. Os professores não têm muitos aparatos didáticos para ensinar, pautando de métodos tradicionais.

Contudo, com o avanço das tecnologias e pesquisas em educação, novas formas de ensinar têm surgido nos últimos anos. Uma delas é chamada de metodologias ativas. O aluno passa a ser o cerne da aprendizagem, não adotando mais uma postura passiva diante do conhecimento. Professor e aluno são colaboradores de um novo saber, em uma atitude colaborativa, incentivando a participação autônoma na construção do saber.

Trabalhar desta forma traz uma série de benefícios aos alunos, pois eles adquirem mais confiança e autonomia, enxergam o aprender como algo tranquilo, tornando-se aptos a resolver problemas. Para o mercado de trabalho, eles entram mais qualificados e valorizados, pois sabem ser protagonistas de seu aprendizado. (BORGES, 2014; MELLO et all, 2019).

Não há como desconsiderar as mudanças de contexto ao se ensinar seja o que for. No caso da Filosofia, considera-se mais complicado ainda, pois como ensinar a pensar e questionar sobre temas da vida em uma geração imediatista e digital? A dificuldade é grande. Sendo assim, novas formas de ensino devem ser criadas para que se atenda com maior eficácia essas gerações.

Destarte, fomos motivados a buscar as relações entre ensino de Filosofia e as metodologias ativas. Percebeu-se que ainda há poucos trabalhos sobre o assunto e, assim, considera-se de grande importância para a comunidade acadêmica e para o professorado da disciplina. De que forma as metodologias ativas têm ou podem contribuir com um ensino de filosofia mais focado na realidade do aluno da geração Z? Essa é a pergunta que buscou-se responder nesta pesquisa.

Para a composição do artigo, optou-se por duas etapas metodológicas. A primeira é a pesquisa bibliográfica, a fim de caracterizar o ensino de filosofia no Brasil e as metodologias que vêm sendo empregadas, além de caracterizar e identificar as principais metodologia ativas. Em seguida, utilizou-se livros didáticos de Filosofia, como os cadernos "SP faz escola" da Secretaria de Ensino do Estado de São 
Paulo e duas edições de "Filosofando". Nossa intenção inicial era realizar questionários com professores, mas por conta da pandemia do novo Coronavírus, achamos melhor trocar o material de análise.

Este trabalho está estruturado em três capítulos. No primeiro, será apresentado o panorama do ensino de Filosofia no Brasil. Será apresentado como ele se iniciou, legislações principais e qual é a situação atual. No segundo, trataremos das metodologias ativas, apresentando os principais tipos e como elas se aplicam em sala de aula. No terceiro, serão analisados os livros didáticos, de forma a verificar como os manuais de professores estão indicando as ações pedagógicas e soluções didáticas. Os três, com a conclusão, buscarão responder à nossa indagação.

Acredita-se que os livros trazem atividades com as metodologias ativas, mas que ainda não se lecione uma aula toda dentro da metodologia. Crê-se ainda que a sua adoção contribuí para um ensino mais dinâmico e questionador, de forma a atender de melhor forma com os objetivos da Filosofia como disciplina.

\section{O ensino de filosofia no brasil: contextualização e pressupostos teóricos}

Histórico da filosofia no brasil

A Filosofia é a mais antiga das áreas do conhecimento. Seus estudos são base para praticamente todos os outros saberes. Iniciada na Grécia Antiga, ela acompanhou a história, tendo o amor ao pensamento como gênese de sua atividade. Para os filósofos, como ressalta Morente (1980), é uma atividade centrada em perguntas reflexivas. Entretanto, tais questões não caracterizam em si a atividade filosófica. É notório que se saiba identificar os tipos de perguntas e elementos típicos da reflexão, sem cair em lugar-comum.

No nosso país, os primeiros a ensiná-la foram os jesuítas, influenciados pela sua formação nos mosteiros europeus. Grandes nomes, como o do jesuíta Francisco de Faria e do Pe. Vieira, contribuíram para que a história da filosofia começasse a se instaurar em nosso país já no século XVIII. Por muito tempo, figurou como um ramo da filosofia portuguesa. Com a independência e a república, o país conseguiu maior liberdade em relação à Portugal, dando margem à construção do pensamento brasileiro. Foi na Universidade de São Paulo que a nossa filosofia criou raízes, com nomes como Antônio Cândido, Marilena Chauí, Giannoti, Pe. Vaz, entre tantos outros (ARAÚJO, 2018).

A inserção do componente curricular enfatizava os filósofos do período antigo, de maneira a formar uma elite, cada vez mais influenciada pelas novas ideias que vinham da Europa. César (2012) ressalta que ela foi oferecida nos currículos por muito tempo como forma de manter status, de forma que seu ensino fosse basicamente enciclopédico, sem nenhuma pretensão maior. 
Com as reformas educacionais do século XX, a disciplina sofreu muitos baixos, sendo deslocada para o rol de optativas ou ainda excluída do currículo, como aconteceu durante o regime militar por considerá-la subversiva e comunista. A escola neste período se manteve elitista e acadêmica e teve seu campo de atuação cada vez mais limitado. A Filosofia então sofreu uma dura queda, quando os militares à época justificaram, por meio da LDB de 1971, que o ensino deveria ser mais tecnicista e a ela não cabia no momento. Em seu lugar, ofertou-se "educação moral e cívica" e "organização social e política do Brasil” (CÉSAR, 2012).

Nos anos de 1980, com a abertura política, Filosofia e Sociologia foram voltando timidamente aos currículos escolares do então $2^{\circ}$ grau, mas ainda longe de ser o que os professores almejavam. Na LDB $n^{\circ}$. 9.394 de 1996, elas são inseridas no currículo novamente, pois, como afirma o artigo 36, os alunos devem “dominar os conhecimentos de Filosofia e de Sociologia necessários ao exercício da cidadania" (GONTIJO, 2015).

Até os dias de hoje, se associa muito Filosofia com exercício da cidadania, como se lê na LDB. Contudo, as práticas mostram o contrário. A adoção do modelo francês - a abordagem histórica - até os dias de hoje tem levado os alunos a repetição de saberes de Filosofia, sem cumprir o principal papel: construir conhecimentos acerca da realidade. Ela não é só um saber enciclopédico, como muitos professores praticam. É algo que demanda um pensar mais elaborado que vai muito além de esquemas e rigor tradicionalista das escolas. É preciso ensinar a pensar, de forma que se exprima uma visão coerente do vivido (GALLO, 2013).

O exercício da Filosofia é um instrumento que dá lugar a um pensamento singular, na experiência de interrogação, irrenunciável e sobre a própria experiência. O fazer filosófico deve privilegiar o emancipar e desenvolver todas as consequências desse reconhecimento de educar sem subestimar, seguindo o princípio da igualdade das inteligências, "existo, logo penso", ou seja, nessa visão de que todos os seres humanos possuem igualdade de capacidade, e essa será libertadora a partir do desenvolvimento da potência não sendo inferior a inteligência. Todo filosofar é um recomeço, numa tentativa de superar o mestre.

No tópico seguinte, essa questão metodológica será mais bem tratada.

\section{Os métodos de ensino de filosofia}

Faz pouco tempo que Filosofia é obrigatória no currículo do Ensino Médio. Esse ambiente de tensão causa incertezas ao professor, que sofre com o querer-fazer-a-diferença, e à instituição, que muitas vezes o engessa. A realidade escolar é de dúvidas, pessimista e ainda não se tem o aporte necessário. Muito se indaga do porquê de estudá-la, ou até mesmo da sua utilidade. Cerletti $(2009$, p. 52) resolve essa questão propondo que "o professor-filósofo poderia propor perspectivas de análise que tentam desnaturalizar o que 
parece óbvio, permitindo assim construir olhares problematizados da realidade". O mesmo autor ressalta que ela nunca deverá ser "mais do mesmo", já que cada aula é única, assim como as reflexões dela formadas.

Todavia, o professor de Filosofia não pode desanimar diante das dificuldades. Ele é uma das pessoas que têm o poder de ajudar os alunos a se emanciparem intelectualmente, sendo donos de seu próprio destino. Ninguém é dono da verdade, mas é possível investigar as mais diversas existentes. E o professor quem ajudará os alunos a irem além, equilibrando as diferenças de inteligências.

Falando em mestre, Cerletti (2009) nos atenta para os trabalhos de Sócrates, o $1^{\circ}$ professor de Filosofia que nos ensinou a relação entre saber e ensinar, praticando com os outros a relação com o saber e com a ignorância. Seus alunos aprenderam não saberes pontuais, mas uma relação direta com o saber.

Guido, Gallo e Kohan (2013) fizeram um grande levantamento para a produção do material didático do curso de Ensino de Filosofia no Ensino Médio, para a Universidade de Brasília. Eles concluíram que a Filosofia tem sido ensinada de três formas prioritariamente: (1) histórica, (2) temática e (3) problemática.

A abordagem histórica da Filosofia é aquela que vem sido utilizada há mais tempo nas academias e, por conseguinte, vem sido utilizada na escola de ensino básico há mais tempo. Por esse víeis, os saberes são organizados historicamente e apresentados aos alunos por meio de textos originais de seus autores, na sua maioria. A atitude filosófica fica restrita ao texto clássico, pela qual se elimina uma série de determinações que são excluídas da apreciação da obra. $\mathrm{O}$ aluno é levado a compreender o sistema filosófico para extrair daí a sua verdade formal, com enfoque conteudista. A abordagem histórica calca-se no rigor metodológico e foi por muito tempo praticado por religiosos, chegando a uma "antropologia filosófica" (GUIDO, GALLO E KOHAN, 2013).

Hoje em dia, a abordagem temática vem sendo utilizada como uma alternativa à histórica. Com o aumento das licenciaturas em Filosofia no país, bem como aproximação com outras academias estrangeiras, que propiciam aos professores brasileiros valiosas trocas de práticas e métodos docentes. O professor pode organizar suas aulas por meio de textos dos próprios filósofos ou de comentadores, bem como uma série de apoios, como vídeos, músicas, textos literários, histórias em quadrinhos, imagens etc. (p. 120).

É uma forma mais contextualizada de tratar a Filosofia, na qual o professor consegue optar por um ensino mais calcado na transmissão da tradição filosófica ou por um ensino que invista mais diretamente no trabalho do próprio estudante. É um ensino que se aproxima com as metodologias ativas de aprendizagem e que consegue, se bem aplicado, a levar o aluno a refletir sobre o tema estudado e formar o seu próprio conceito, fazendo com que a Filosofia comece com o próprio aluno.

Há ainda, segundo os autores, a abordagem problemática, que parte do princípio de que o fazer filosófico é sempre produzido a partir de problemas, que levam e mobilizam os filósofos a criar seus próprios conceitos. O aluno era levado a responder perguntas à exaustão até conseguir formar os seus 
conceitos. Essa abordagem foi utilizada no Uruguai, mas fracassou por tomar o problema como interrogação e não como dúvida (GUIDO, GALLO E KOHAN, 2013).

Por fim, é importante ressaltar o papel do mestre de Filosofia. Independente da abordagem, ele deve ser alguém que emancipa o aluno, que faça com que a Filosofia comece com o estudante. Ninguém sabe tudo, mas os dois podem juntos construir saberes de modo com que o professor possa até ser superado. Ensinar Filosofia não é uma tarefa das mais fáceis, mas, felizmente, a formação no Brasil tem melhorado muito e os docentes têm tido mais acesso a cursos (como este excelente curso que tenho a honra de ser aluno), além de que a população tem percebido o real valor da disciplina para a nossa vida.

\section{As metodologias ativas de ensino e a filosofia}

Anteriormente, foi visto que o ensino de Filosofia é sofre com a sua instável situação nas escolas brasileiras. Contudo, essa não é a única a necessidade da disciplina. Quando se abrange o termo de ensinar para educação filosófica, como o faz Kohan (2009), entram em pauta métodos e processos de ensino, os quais têm seguido a tradição francesa secular.

Porém, estamos falando de um novo século, em que a tecnologia é parte fundamental da vida de qualquer cidadão. Quando se volta a atenção para o nosso público-alvo, a geração Z, os métodos de ensino são mais importantes, visto que se trata de pessoas ativas, dinâmicas e que não conseguem aprender com o velho arroz e feijão de outrora.

Destarte, as contribuições do campo educacional, sobretudo a pedagogia informática e a educação empreendedora, são importantíssimas para se desenhar novos modelos de ensino. Kohan (2009, p. 70-71) assevera que ensinar a filosofar exige autonomia de várias partes: "autonomia diante de outros saberes, e poderes; autonomia do professor perante instituições; autonomia de quem aprende ante a quem ensina e os outros aprendizes”. Assim, a autonomia é um conceito-chave para um aprendizado mais concatenado com a realidade, mesmo que para isso seja necessário desafiar todo um sistema político-econômico.

Silvio Gallo (2013) reaça tal papel ao dissertar sobre a Filosofia nos "tempos hipermodernos", colocado em aspas pelo autor. Esses se caracterizam por um momento histórico em que "teses e os modelos da modernidade não foram superados, mas hiperbolizados, elevados à enésima potência” (p. 22). Mais adiante, ressalta que nossas salas de aula vivem em tempos cada vez mais acelerados, como em videoclipe da MTV. "Tudo é fruição imediata, sem tempo para o pensamento organizado" (p. 23).

O mesmo autor ressalta que ensinar a filosofar é um exercício da paciência. É uma atividade de insistir no extemporâneo, trazendo inquietações que não são deste tempo. Exercitar Filosofia é uma forma de resistir à aceleração, à fluidez e à falta de tempo para o conceito. Aquele que a ensina, assim, milita nessa resistência e a amplia para mais pessoas. 
Apesar de parecer que se está transmitindo o intransmissível, Kohan (2009) salienta que quem ensina afirma um gesto. Este pode ou não ser percebido pelo aluno que, eventualmente, o recria. Ensinar e aprender Filosofia se relacionam a uma sensibilidade para compartilhar um espaço no pensamento, dando lugar no pensamento a um movimento que interrompe o que se pensava e começa a pensar novamente. $\mathrm{O}$ professor seduz o aluno a acompanhá-lo, inaugurando uma nova relação.

Diante disso, esse processo de sedução do aluno do século XXI é diferente por se tratar de "tempos hipermodernos"1, o que demanda novas metodologias. Nos estudos pedagógicos atuais, se emprega as metodologias ativas de aprendizagem. Por este termo, entende-se como maneiras de desenvolver o processo de aprender, como forma de conduzir uma formação mais crítica a futuros profissionais. Para Borges e Alencar (2014), seu uso favorece a autonomia, desperta a curiosidade, estimula a tomada de decisões individuais e coletivas, essenciais para práticas sociais do estudante.

Berbel (2011) complementa que os alunos não são tomados como marionetes, tal que se fizera por muito tempo. Age-se de forma natural e intencional, de forma que o problema a ser estudado seja tomado na sua totalidade e uma solução seja investigada da melhor forma. Hábitos são aprendidos para serem usados em ação, além de conhecimentos aprendidos para guiar a ação. "Quando combinados com a motivação, o sujeito percebe que foi ele o causador da mudança desejada", ressalta a autora (p. 26).

Como primeira premissa, o aprendizado deverá ser focado no aluno. É ele quem faz as tarefas, investiga, cria, enfim, que produz para a sua própria construção do conhecimento. O professor é aquele que propõe situações reais, transforma-as em problemas para que os alunos possam resolver. Durante as tarefas, o docente é responsável pelo suporte ao aluno, mas nunca deve fazer a tarefa para ele. É um mediador do conhecimento (KÜLLER, 2013; MELLO et all, 2019a).

As características gerais são representadas na Figura 1.

Os conteúdos são integrados, podendo haver interdisciplinaridade de forma bastante proveitosa para os alunos e professores. Pode-se tomar conhecimentos de diversas disciplinas e integrá-los ao desenvolver as tarefas dos alunos. Outro ponto crucial é que não se pode deixar de levar em consideração aquilo que o estudante já tem na sua bagagem, o que o levará a resolver problemas com maior autonomia (MELLO et all, 2019a; MELLO et all, 2019b).

\footnotetext{
"As metodologias ativas têm o potencial de despertar a curiosidade, à medida que os alunos se inserem na teorização e trazem elementos novos, ainda não considerados nas aulas ou na própria perspectiva do professor. Quando acatadas e analisadas as contribuições dos alunos, valorizando-as, são estimulados os sentimentos de engajamento, percepção de competência e de pertencimento, além da persistência nos estudos, entre outras. [...]” (BERBEL, 2011, p. 29)
}

${ }^{1}$ Aspas do autor Sílvio Gallo. 
Figura 1: Características das metodologias ativas.

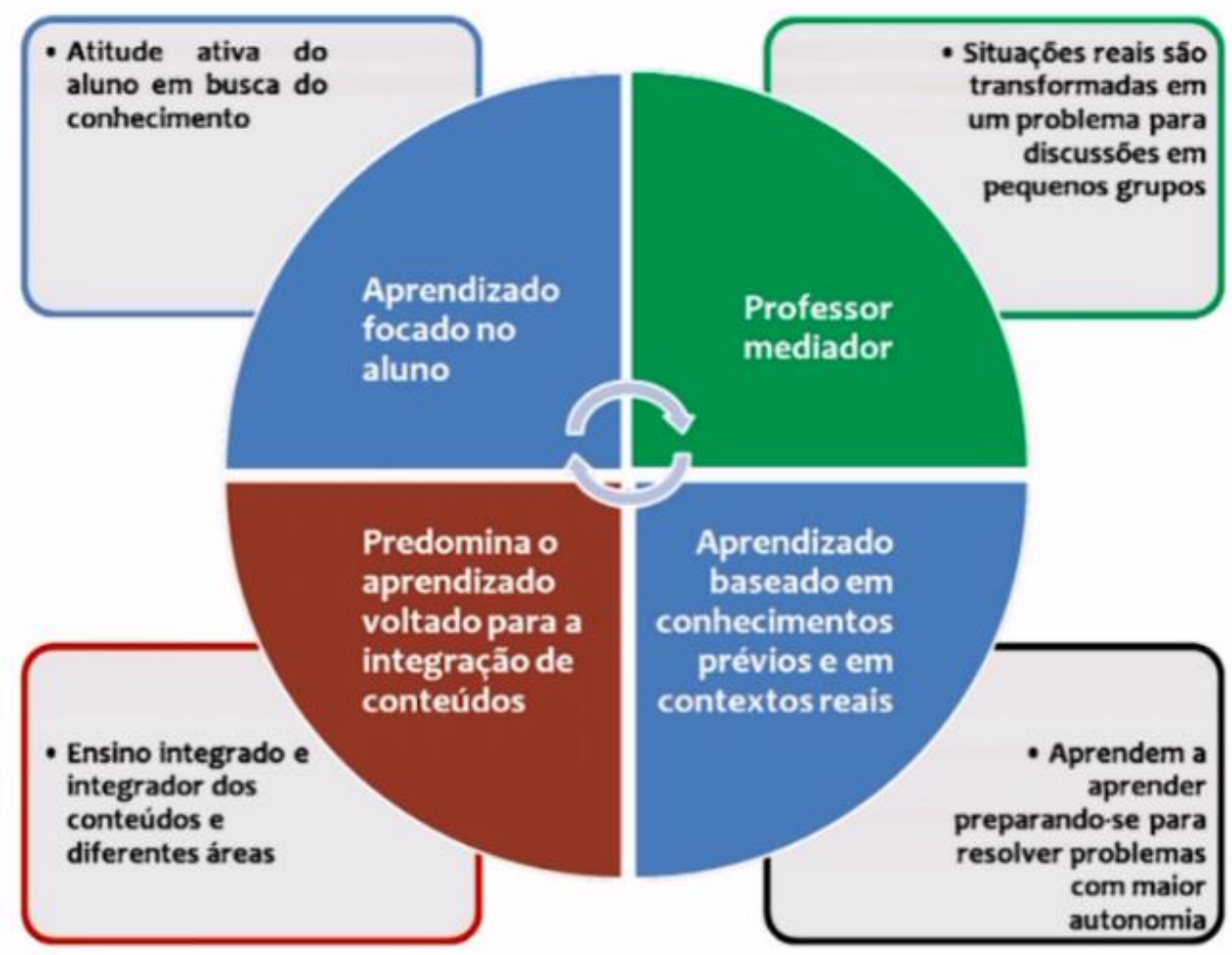

Elaborada pelo autor.

Como se pode notar, há muitos benefícios ao adotar as metodologias ativas em sala de aula. Para que o aprendizado seja mais eficiente, é possível utilizar de diversas técnicas, deixando os momentos do aprender ainda mais dinâmicos. Os tipos mais usados são gamificação, sala de aula invertida, aprendizagem por projetos e o ensino híbrido.

A gamificação é caracterizada pelo uso de jogos e brincadeiras no ensino. Ela é capaz de gerar maior engajamento e motivação na aula, ao promover a sensação de competição ao propor uma competição ou uma resolução criativa de problemas. Ela pode ser usada em associação com o ensino híbrido, que é uma combinação de ensino presencial com ensino a distância, quando realizados em sala de aula. Atividades como rotação por estações, laboratório rotacional, rotação individual são exemplos dessa forma de ensinar (MELLO et all, 2019a).

Já a aprendizagem por problemas, como o nome sugere, é constituída pela construção do conhecimento a partir de problemas discutidos em grupos. Os alunos devem estudar individualmente antes do momento de debate, gerando momentos de autoestudo e maior autonomia, que são praticadas nos momentos em grupo. A participação se torna essencial, de forma a incentivar o trabalho em grupo e a responsabilidade de cada um. Começou a ser usada em cursos de Medicina e hoje é recorrente em todas as áreas do conhecimento (MELLO et all, 2019a). 
Por fim, a sala de aula invertida é vista como uma das mais eficazes técnicas. A lógica da sala de aula é totalmente redesenhada. $\mathrm{O}$ aluno estuda em casa, tendo o seu primeiro contato. Na sala de aula, esse conhecimento é potencializado por meio de atividades integradoras em grupo, que são responsáveis por fazer com que o aluno coloque em prática o conteúdo previamente estudado. Berbel (2011, p. 33) acredita que a relação teórico-prática é constante, além de se quebrar paradigmas, como o do professor como detentor único do saber. Há uma dinâmica de ação-reflexão-ação, sendo transformadora em algum grau. "Nesse sentido, o percurso é percebido como uma forma de exercitar a práxis, entendida como uma prática consciente, refletida, informada e intencionalmente transformadora", complementa a autora.

Em linhas gerais, pode-se dizer que as metodologias ativas são bastante disruptivas ao promover o câmbio do professor como centro da aprendizagem para o aluno como tal. Colocá-lo para fazer, dentro ainda do conceito de cultura maker, é uma forma de responder aos anseios da sociedade em constante revolução tecnológica, sobretudo agora pós pandemia. A aula de Filosofia se torna uma oficina de conceitos, nos dizeres de Gallo (2013, p. 92-93), pois o aprender se dará a partir de ferramentas de diálogo, reflexão, garantindo aos jovens um contato com o instrumento conceitual. A aula é um espaço de transmissão de conhecimentos, mas que o aluno não deva ser expectador, mas agente ativo desse processo, produzindo e criando. "A própria Filosofia é a matéria para produção de novos conceitos", complementa o mesmo autor.

E como auxiliar neste processo, o professor tem o livro didático como uma importante ferramenta de trabalho, sobretudo nas escolas mais periféricas. A abordagem do livro influenciará muito o fazerdocente, conforme se discutirá no próximo capítulo.

\section{Análise dos livros didáticos}

O livro didático é um instrumento de grande valor educacional. Está presente nas escolas brasileiras há muito tempo, tendo sua presença intensificada após a década de 1980. Antigamente, era privilégios de poucos, mas com programas governamentais como o FNLD, seu acesso foi capilarizado para o país todo nas escolas públicas, contribuindo para a melhoria do ensino.

$\mathrm{Na}$ área de Filosofia, os livros ainda estão no início, se comparar com outras disciplinas. Pela inconstância da presença no Ensino Médio, as editoras não investem muito na área, tendo o mesmo livro diversas edições há muito tempo. Isso acontece, por exemplo, com o já clássico "Filosofando: Introdução à Filosofia”, da Editora Moderna, que está na $4^{\mathrm{a}}$ edição, datada de 2009. Contudo, a primeira edição é da década de 1980.

Esta obra apresentou uma progressão em relação às edições. Sua primeira abordagem foi puramente histórica, se concentrando nos movimentos de Filosofia ao longo dos anos. Textos transcritos em linguagem 
mais acessível eram a principal fonte de informação, seguidos do famigerado questionário. Os alunos tinham uma atitude clássica de ler o livro, memorizar informações e reproduzi-las em provas. Esse ciclo foi herança da educação tecnicista implantada pelo regime militar nos anos de 1960 e 1970, em que pensar não foi tão valorizado, a ponto de promover um embate ideológico contra o governo.

A edição mais recente apresenta significativas melhoras. A abordagem do livro passou a ser problemática, pois capítulos estão inseridos dentro de uma unidade, que por sua vez, retrata um problema filosófico. Por exemplo, a unidade sete trata sobre Estética, trazendo consigo cinco capítulos amplos sobre o tema. Os filósofos são inseridos por meio de textos autênticos e de teorias escritas pelas autoras. Há vários recursos visuais, como abundância de imagens, histórias em quadrinhos, ícones, cores vibrantes e entradas de texto, numa tentativa de aproximar o conteúdo ao seu público-alvo. Há ainda umas caixas chamadas "Para refletir", que fazem com que o aluno pare e reflita sobre aquilo que está a ler.

Na página reproduzida na íntegra, pode-se notar a diagramação, com uso de tipologia mais adequada à faixa etária, imagens alusivas ao universo do público, além de dois destaques: (1) a entrada marrom "para refletir", que traz o texto para o cotidiano do aluno e (2) no rodapé, uma entrada menor explicando um termo que pode ser de difícil compreensão.

A nova edição, apesar de bastante completa, ainda não é suficiente no que tange às metodologias ativas. Com o tipo de linguagem empregada e atividades propostas, o livro é um excelente instrumento para autoestudo, mas de difícil uso em formas mais ativas. Acredita-se que no caso de sala de aula invertida, seria uma excelente referência para os alunos, de forma a oferecer bom repertório filosófico e cultural para futuros debates. Contudo, para projetos e uso híbrido, não seria adequado, pois é somente uma obra referencial. Mesmo assim, não se pode negar a qualidade da obra, a sua tentativa de ser completa e de enriquecer o repertório filosófico e cultural do estudante. 
Figura 2: Reprodução integral de uma página da versão atualizada da obra "Filosofando".2

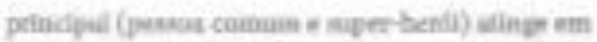

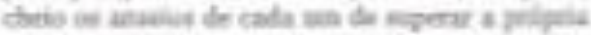

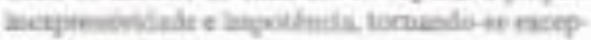
cìnat epishors:

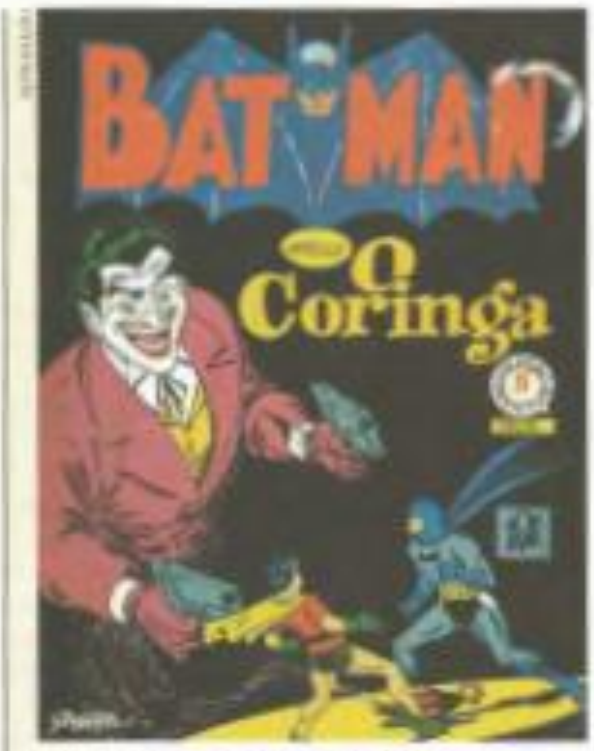

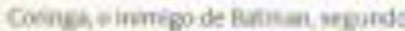

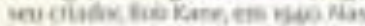

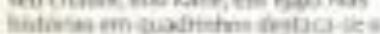

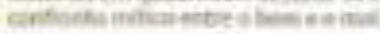

Os ouska de fods rotomars os mitse unineskis

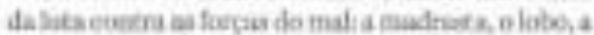

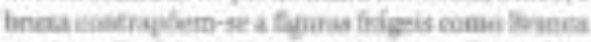

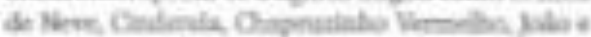

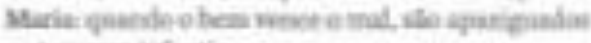
ge tremores valantis.

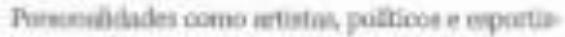

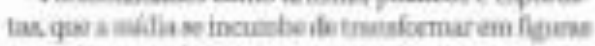

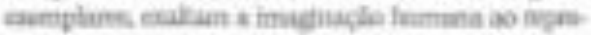

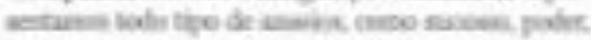

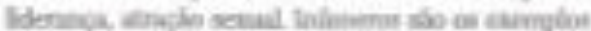

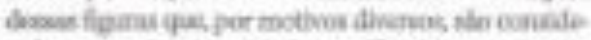

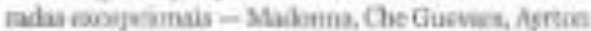

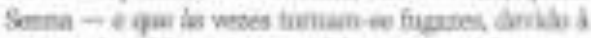

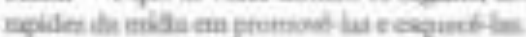

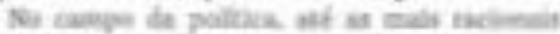

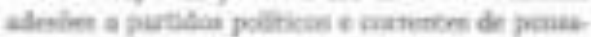

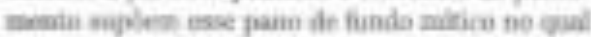
nos movcinos ane direchlos a vilures qoe só poscriormeste jaifen ser explicitailos peta nstio

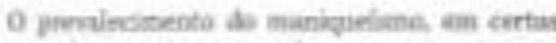

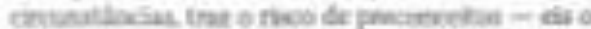
lakle nankers de alpuss mitos - avile k tendto

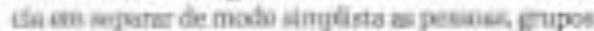
ou nacsualidades, come antepontas. hot esenpla o maisme de Hitler afindasse a partir ide intefa da

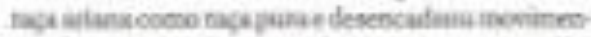

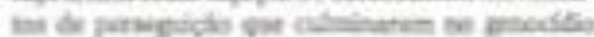

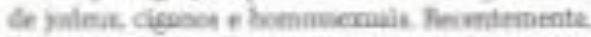
dians die ataques do pupes terrorita da N Maeda me Rirados Unidos, wrials hi quem genenalse a avoliache atritnocinde a mal a tade pewarinite

\section{Tax Erith}

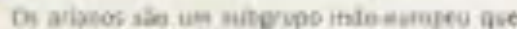

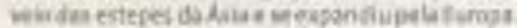

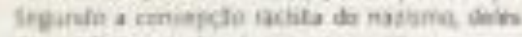

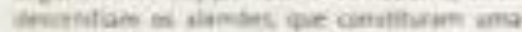

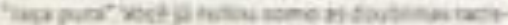

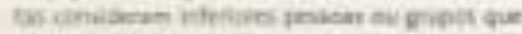
steatrosas dimines!

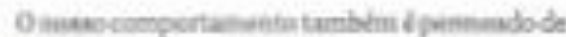

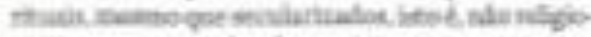

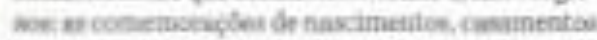

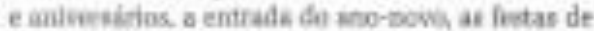
formahira ede debritures, ce trotes de calcurces non

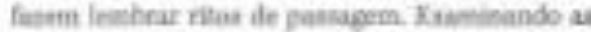

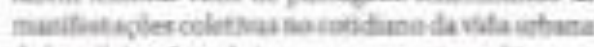

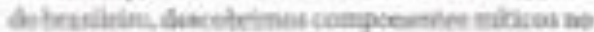
carnwal t ne firtobel, bejos come manifiedacole. do imapinavio mactond e du cxponsh de forças itouscientes.

\section{Para flnalizar..}

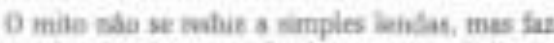
porte de vida humana desde nus trimintios , ainla persiste no mese cotidiano come ume das Eeporlanias posshait do esiatir lnumans vapns

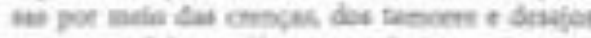

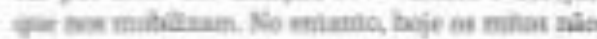

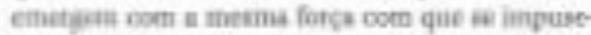

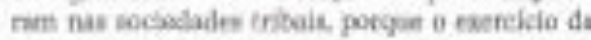

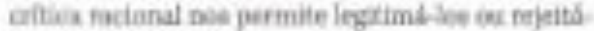

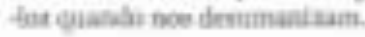

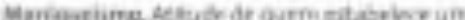

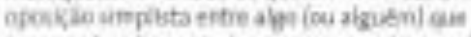
inpenenta o tetn sizitreque represetia ema

Outra obra bastante popular na atualidade foi produzida pela Secretaria da Educação do Estado de São Paulo. A obra foi lançada em 2020, como parte das medidas do governo para manter os estudos diante

\footnotetext{
${ }^{2}$ Fonte: ARANHA E MARTINS, 2009, p. 33.
} 
da pandemia do Coronavírus. Os alunos recebem um exemplar bimestral com todas as disciplinas, tal qual o professor.

Figura 3: Reprodução de página no caderno do segundo bimestre ${ }^{3}$

numa concepça que nso pode penetrar na vida prática e na sçaso, desvanece quando o filbsofo sai da sombra e psenetra no da claro, nom seus prinópios podem manter facimente qualquer influència sabre nossa conduta e nossos costumes.

Ensio sebre o Entendimenta Hamana. David Hume²

- Segundo Hume, a Fllosofia moral (ou a Clência da Natureza Humana) apresenta-se de duas maneiras: uma crienta-se para a açlo e outra para racionalidade. Oual é a mais apreciada pelo autor? identifique as passagers do tecto capases de comprovar a sua resposta.

- "Abstrusa" é uma palavra recorrente no texto (há trếs ocorrênciasi), qual é o seu significado? Qual sua importáncia para compreensalo do texto?

- Para apresentar a filosofia moral e os seus modos, Hume faz uso da "palavra de Deus" ou outro elemento que remete a alguma religiso? Oual é a base do argumento de Hume para expor as duas maneiras de fazer filosofia moral?

- Em grupos, busquem imagers que caracterizam os textos lidos e montem um painel capaz de liustrar as marcas do discurso religioso e do discurso filcebifico.

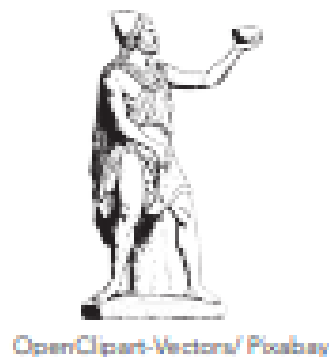

Qual é o espaço da religišo nas questóes de Estado no mundo contemporalneo? No mundo antigo, muitas narrativas mestram como os deuses acabam decidindo questóes que justificam o poder político ou a vittórla numa disputa como, por exemplo, na narrativa da Guerra de Tróla. Na Europa, no periodo medieval, o poder politico era motivo, às vezes mals, as vezes menos, de disputa entre o clero e os reis. No mundo contemporàneo, ainda temos exemplos de Estados Teocríticos? Quais sto as suas caracteristicas mais marcantes? Pesquise e responda!

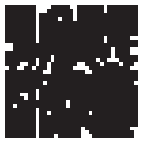

Iliada e Odinasia

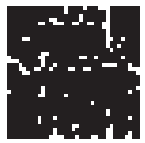

Dialogo aem Frantain $-M$. Foucault a a Revolucibo ranianat

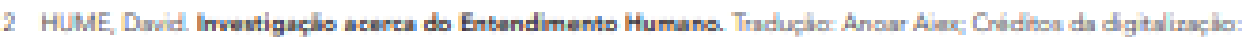

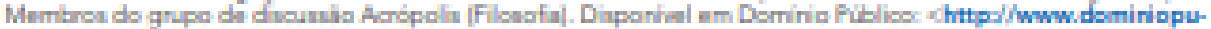
blico gov. bridownload/taxto/cro00627 pdf; Acenso am 2003/2019

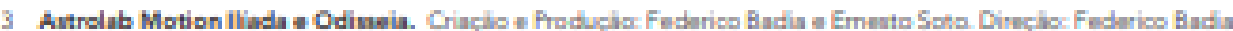

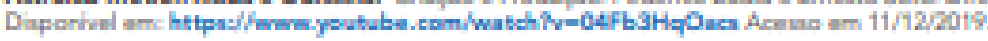

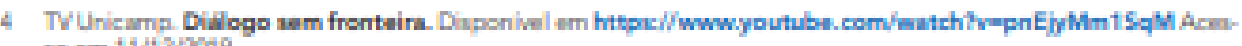
wo am $11 / 12 / 2019$

${ }^{3}$ Fonte: https://alfredoreisviegas.files.wordpress.com/2020/06/3c2aa-serie-2bim.pdf 
Apesar de apresentar estrutura mais simplificada que o livro anteriormente analisado, os cadernos paulistas apresentam textos explicativos, textos autênticos, ilustrações, QR codes e links para que o conteúdo seja mais bem explorado pelo aluno.

Pode-se notar que há mais perguntas sobre o texto (no exemplo, de Hume) e uma tentativa de trazer para o cotidiano do aluno, com as perguntas localizadas no centro da página. Elas poderiam dar margem a uma série de debates em sala de aula e até pautarem uma aula invertida. Uma vantagem deste material em relação à outra obra é que este apresenta QR codes com links mais diretos e atualizados. O próprio ato de leitura do código já demonstra que o aluno está fazendo algo pelo seu ensino.

Ele também é melhor concebido na questão de usabilidade e do professor como apenas um guia para o aluno. É um material de auto-estudo, mas que pode gerar situações mais práticas de discussão. Além disso, foram concebidos de forma integrada com todas as outras disciplinas do bimestre, o que representa mais uma importante característica para a metodologia ativa.

Contudo, ambas obras não ajudam o aluno a construir sua própria conceituação sobre os termos. Gallo (2013) recomenda que um conceito nunca é dado, sempre criado. Na aula de Filosofia, se concebe conceitos tal qual se faz filhos, da onde vem a noção de concepção. $\mathrm{O}$ autor ainda ressalta que é fundamental tomar as aulas de Filosofia como uma atividade, nos remetendo "para uma dimensão em que o processo não se separa do produto; um só pode ser tomado com o outro e pelo outro" (p. 62).

Adotar conceitos da metodologia ativa é uma maneira fazer o que recomenda Cerletti (2009), não a ensinar como nos fora, mas de forma concreta, com variado panorama de condicionamentos e influências. É ir além de meras configurações de pensamento, mas de construção de conceitos e tomada de consciência de sujeitos. E o material didático é uma ferramenta importantíssima nesse processo.

\section{Considerações Finais}

O filósofo é o amigo do conceito, mais ainda, o conceito em potência, como disse Deleuze e Guattari (2010). Ensinar tal disciplina é mais do que fabricar conceitos, pois eles não são achados ou produtos que se compram em qualquer lugar. É “conhecimento por puros conhecimentos” (p. 13).

Vivemos em um país em que a educação nunca recebeu a atenção que merece. Quanto à Filosofia, o caminho é ainda mais árduo, pois sofreu com legislações descabidas ou tiranos do pensar. Ser docente é um ato de rebeldia contra um sistema que almeja formar não um sujeito capaz de problematizar a sua realidade, mas sim, capaz de tarefas operacionais. Destarte, a pesquisa voltada para o ensino é ainda mais audaciosa, pois propõe melhores caminhos de se estudar o fato filosófico.

Buscou-se neste trabalho traçar um panorama da educação na atualidade. São tempos difíceis, de mudanças bruscas à velocidade da luz. Preparar-se para elas é quase impossível, pois se aprende muito mais 
na prática que na teoria. Isso é resultado do mundo globalizado que ainda resultou em uma geração egoísta e imediatista.

As metodologias ativas, assim, são uma exímia possibilidade de atender a várias ânsias sociais: aprender fazendo, pensando, colaborando, criando. Dessa forma, é possível preparar melhor um estudante para a vida pós-escola, buscando a autonomia na sua formação. As técnicas são eficazes e transformam o aprender em uma atividade significativa e prazerosa. A geração Z só se beneficia disso, pois conseguem ter um ensino de maior qualidade e alinhado com o futuro.

Contudo, percebemos que ainda os materiais didáticos não estão voltados para este novo mundo. Eles apresentam textos bem completos, em especial a obra "Filosofando", mas caminham para uma abordagem historicista e temática, enquanto deveria ser mais problemática. Diante disso, cabe ao professor a tarefa de transformar a sua sala de aula, começando a mudança pela sua sala.

O tema é bastante relevante, tal qual a necessidade de fazer da educação a arma mais poderosa de mudança. Percebemos ainda escassez de bibliografias sobre o tema, o que nos leva a crer a necessidade de maior aprofundamento em estudos e práticas. Quando estivermos seguros, pesquisar em sala de aula é uma maneira de criar paradigmas na educação. Um novo conhecimento para o aluno é um ganho excepcional na sua vida.

Por fim, gostaria de ressaltar a necessidade de formação do professor. De nada adianta a escola adotar excelentes metodologias se o mestre não as domina. Para um ensino de sucesso, todos devem estar engajados e lutando pelo mesmo ideal. E o docente de Filosofia deverá forçar seu aluno a pensar, pensando com ele, ou contra ou apesar. O importante é pensar e, por conseguinte, criar conceitos.

\section{REFERÊNCIAS}

ARANHA, Maria Lúcia de Arruda; MARTINS, Maria Helena Pires. Filosofando: Introdução à filosofia.

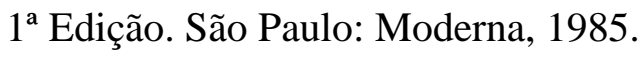

ARANHA, Maria Lúcia de Arruda; MARTINS, Maria Helena Pires. Filosofando: Introdução à filosofia. $4^{\text {a }}$ Edição. São Paulo: Moderna, 2009.

ARAÚJO, Bernardo Goytacazes. A filosofia no brasil, na perspectiva de Ivan Domingues. Edição Especial Vol. 2 Atas do XII Colóquio Antero de Quental. Saberes Interdisciplinares, Ano XI, nº 22, jul.dez./2018. Disponível em: <https://is.gd/y5xUx8>. Acesso em 01.set.2020.

BRASIL. Decreto 5692. Lei de Diretrizes e Bases da Educação, 1971.

BRASIL. Decreto 9394. Lei de Diretrizes e Bases da Educação, 1996.

BRASIL. Decreto 11684. Altera o art. 36 da Lei no 9.394, de 20 de dezembro de 1996, 2008. 
BORGES, Tiago Silva; ALENCAR, Gidélia. Metodologias ativas na promoção da formação crítica do estudante: o uso das metodologias ativas como recurso didático na formação crítica do estudante do ensino superior. 2014. Disponível em:< https://is.gd/953wBu >, Acesso em: 22.mar.2020.

BERBEL, Neusi Aparecida Navas. As metodologias ativas e a promoção da autonomia de estudantes. 2011. Semina: Ciências Humanas e Sociais. v. 32, n.1 Disponível em: 〈https://is.gd/RvDpFG〉. Acesso em 25.abr.2020.

CERLETTI, Alejandro. O Ensino de Filosofia Como Problema Filosófico. Trad. Ingrid Müller Xavier. Belo Horizonte, Editora Autêntica, 2009.

CÉSAR, Renata Paiva. O Ensino de Filosofia no Brasil. Revista Pandora Brasil, nº. 38. 2012.

Disponível em: <https://is.gd/aRtZAm>. Acesso em: 14.jun.2020.

GALLO, Sílvio. Deleuze e a educação. 2 ed. Belo Horizonte: Autêntica, 2008.

GALLO, Sílvio. Metodologia do ensino da filosofia: uma didática para o ensino médio. Campinas/SP: Papirus, 2012.

GONTIJO. P. As Filosofias nos Currículos Estaduais de Ensino Médio in Filosofia e ensinar filosofia / Organizadores: Marcelo Carvalho, José Benedito de Almeida Junior, Pedro Gontijo. São Paulo:

ANPOF, 2015.

GUIDO, Humberto; GALLO, Silvio; KOHAN, Walter O. Princípios e possibilidades para uma metodologia filosófica do ensino de filosofia: história, temas, problemas. In: CARVALHO, Marcelo. CORNELLI, Gabriele (org.). Ensinar Filosofia. Volume 2. Cuiabá, MT: Central de Texto, 2013, p. 105128.

JENKINS, Henry. Cultura da convergência. 2.ed. São Paulo: Aleph, 2009.

KÜLLER. A. Metodologia de desenvolvimento de competências. Rio de Janeiro: Senac Nacional, 2013.

MAZZOTTI, Tarso Bonilha. Filosofia da Educação: uma outra filosofia? PERSPECTIVA.

Rondonópolis, V. 17, n. 32, p. IS -32, jul./d81. 1999. Disponível em: < https://is.gd/jqXEqP>. Acesso em: mar.de 2020.

MELLO, Cleyson de Morais et all. Metodologias ativas: Desafios Contemporâneos e Aprendizagem Transformadora. São Paulo: Editoria Freitas de Barros, 2019.

MELLO, Cleyson de Morais et all. Ensino por competências. São Paulo, Editoria Freitas de Barros, 2019.

MORAN, J. M. A educação que desejamos: novos desafios e como chegar lá. 5. ed. Campinas: Papirus, 2014.

MORENTE, Manuel García. Fundamentos de Filosofia. 8. ed. São Paulo: Mestre Jou, 1980.

SIQUEIRA, Caetano Pansani et all. SP Faz Escola: caderno do aluno. $3^{\circ}$ ano do ensino médio, $2^{\circ}$ bimestre. São Paulo: Gráfica Oficial, 2020. Disponível em: <https://is.gd/ZJot0k> Acesso em 10.jul.2020. 